\title{
5 PEDIATRIC PHYSICAL THERAPY
}

Ingresa al Portal de Recursos de Investigación: https://recursosinvestigacion.upc.edu.pe

(1) Escribe el título de la revista en la casilla de búsqueda: Pediatric Physical Therapy, o búscalo alfabéticamente (letra P).

Pediatric Physical Theral Buscar Todas A B C DEFGHIJKLMN PR \& T UVWXYZ

Ubica el recurso y dale clic al título. Si estas registrado en el SSO (Single Sing ON) ingresarás directamente, de lo contrario deberás registrarte con tu usuario y contraseña UPC
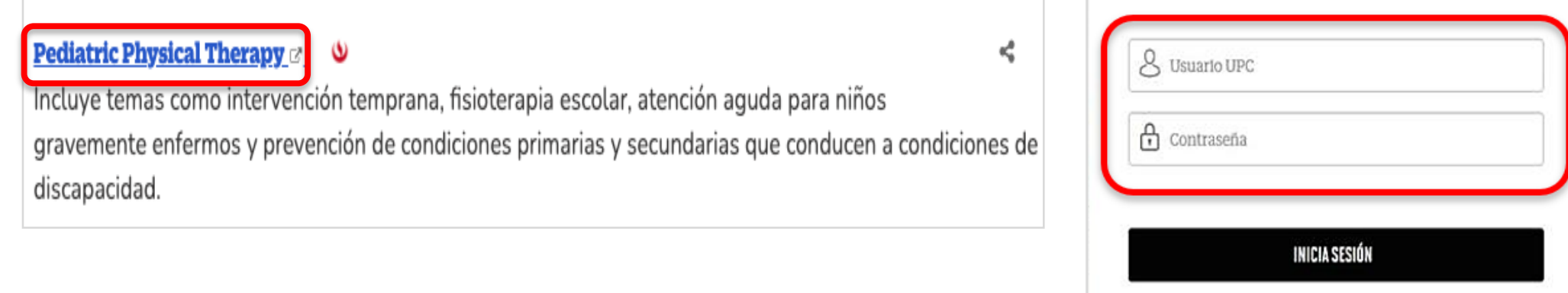

(

¿olvidastetucontrasenara?

3 Escribe tu término a buscar, por ejemplo: Physical Therapy Services.

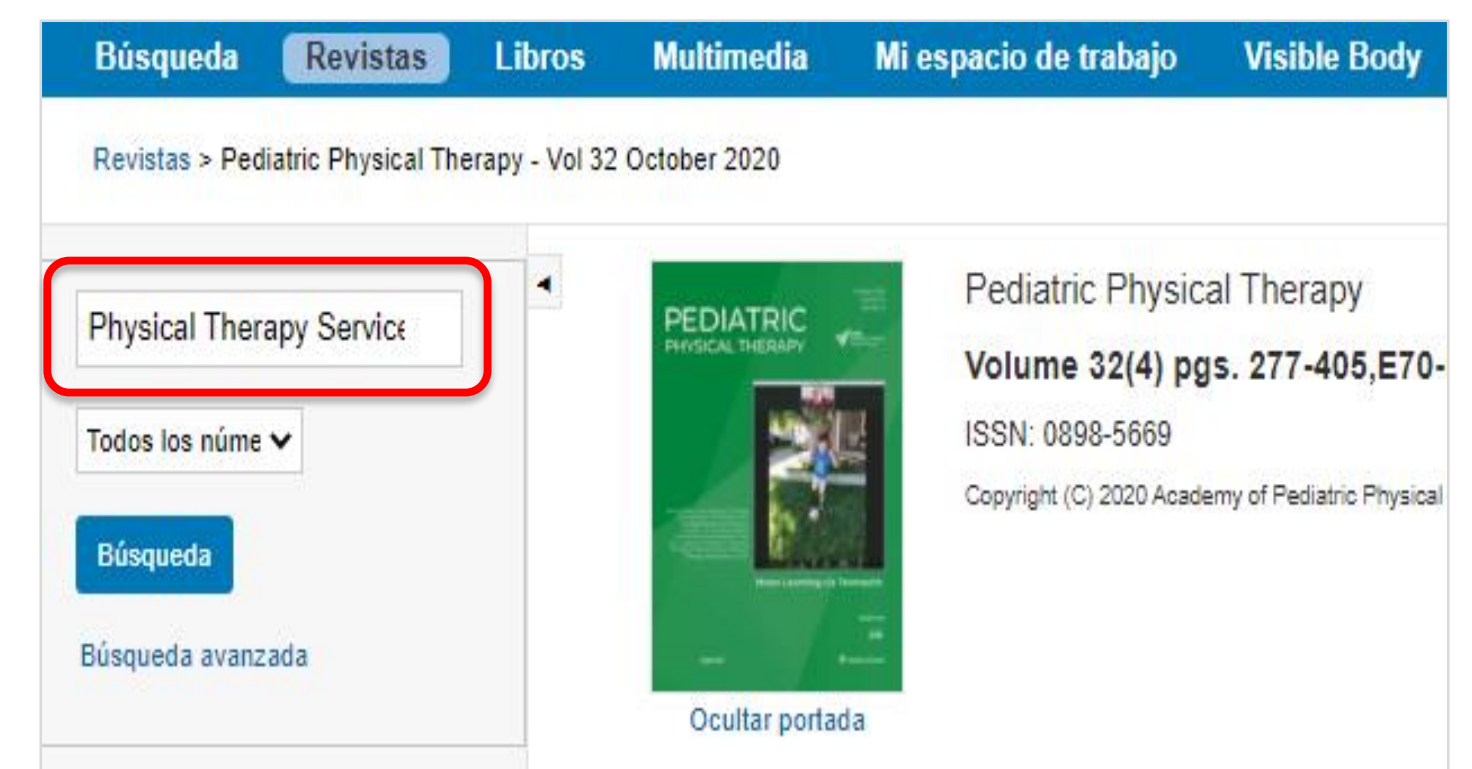

(i) Recuerda:

No es necesario crearte una

cuenta para utilizar todas las

opciones que te ofrece la

plataforma.

En la parte izquierda de la plataforma encontrarás el listado de los volúmenes que tiene la revista. En el centro, el listado de los artículos en base al tema de búsqueda
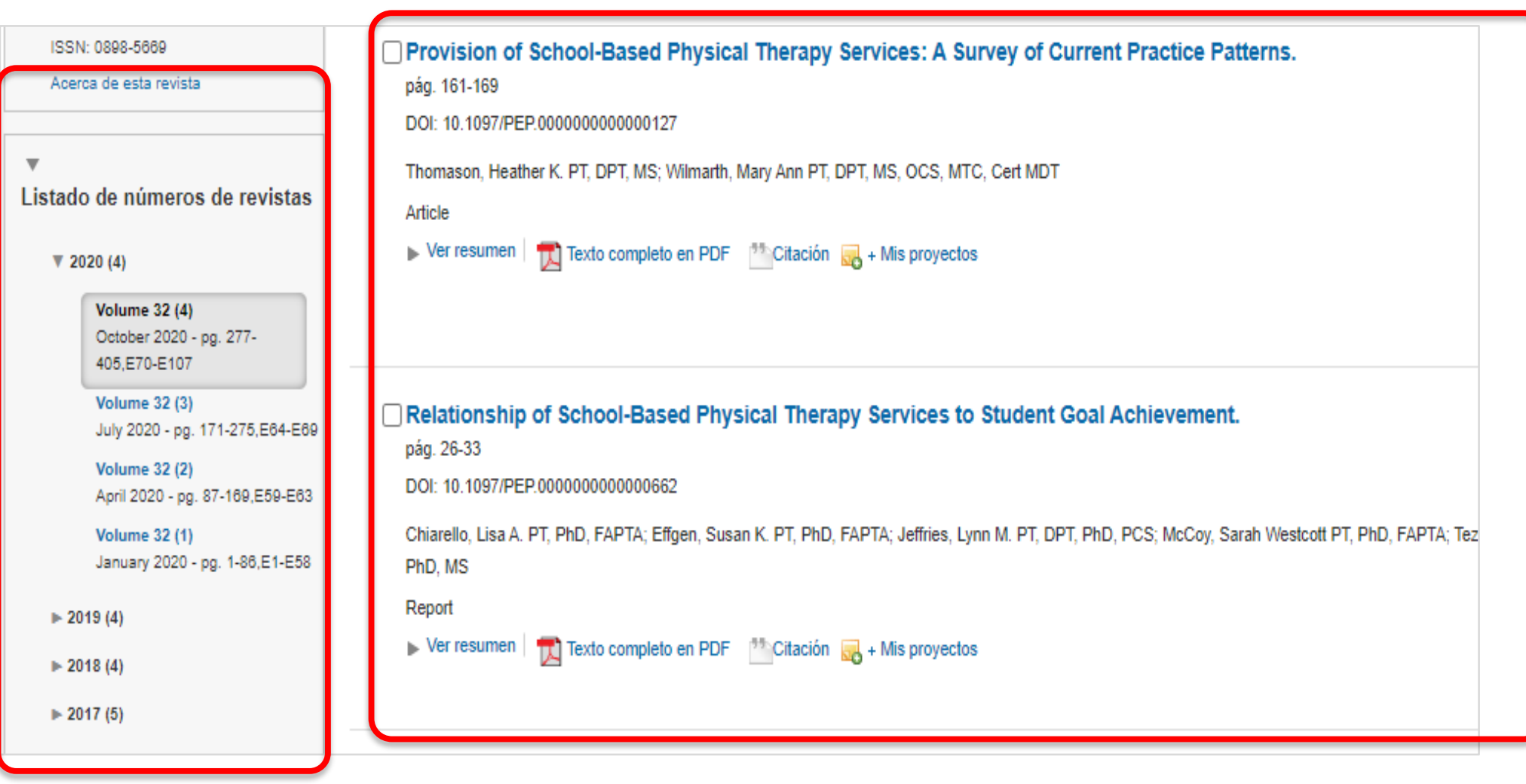

5 Para acceder al artículo, da clic en texto completo en PDF, y si necesitas referenciar el documento, da clic en Citación.

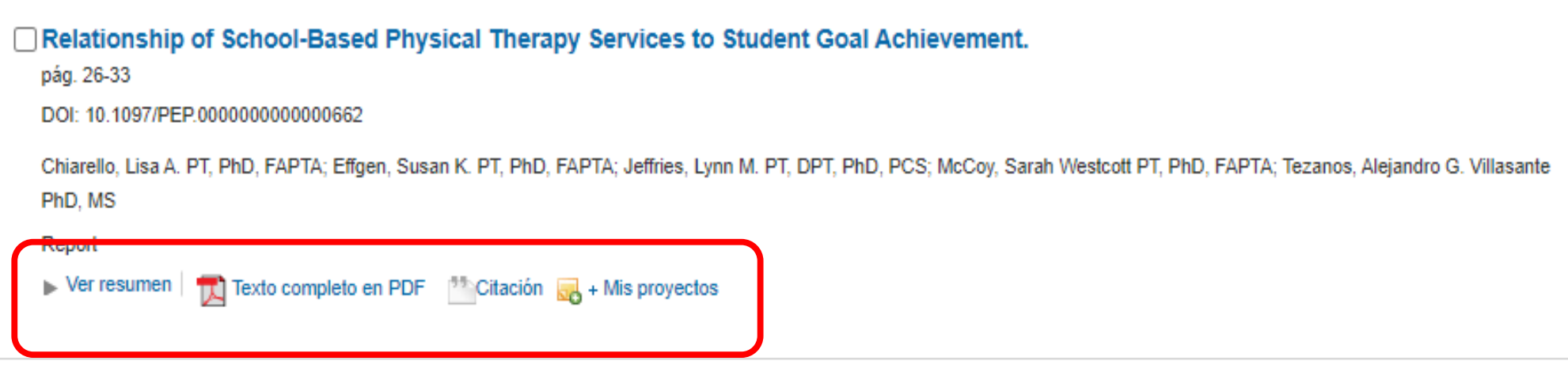

